\title{
Progression of Eales' disease post-partum and long-term follow-up: a case report
}

\author{
Radu Ivanescu' ${ }^{1}$, Ciprian Ivanescu ${ }^{2}$, Kai Januschowski ${ }^{2,3,4^{*}}$ and Augustin Ivanescu ${ }^{1}$
}

\begin{abstract}
Background: Eales' disease is a difficult to treat idiopathic form of retinal vasculitis. We present such a case with peculiar epidemiology in which the only efficient therapeutic approach in order to maintain functional vision was repeated intravitreal dexamethasone implants $\left(\mathrm{Ozurdex}^{\oplus}\right)$. To the best of our knowledge this is the first report of this kind in the literature.

Case presentation: This is the case of a 40-year-old white woman presenting in 2008 with recurrent floaters accompanied by blurring of vision in her right eye and severe visual loss in her left eye caused by retinal detachment; her age at presentation was 30 years. A diagnosis of Eales' disease was made by exclusion. She was stable until 2011 after childbirth (cesarean section). Despite aggressive systemic treatment with steroids, azathioprine, and mycophenolate mofetil, progression of the disease was noted that could only be controlled with repeated intravitreal dexamethasone implants $\left(\mathrm{Ozurdex}^{\circledR}\right)$ injected in her right eye. Her left eye underwent vitrectomy with silicone oil tamponade for tractional retinal detachment with satisfactory anatomical result but vision was limited to light perception.
\end{abstract}

Conclusions: In our case the systemic therapy was much less effective than the intravitreal sustained-release dexamethasone implant $\left(\mathrm{Ozurdex}^{\oplus}\right)$ for reducing recurrences and halting disease progression. We believe that recurrent and severe cases could benefit from this addition to the classic treatment armamentarium.

Keywords: Eales' disease, Recurrent vitreous hemorrhage, Retinal vasculitis, Retinal neovascularization, Photocoagulation, Dexamethasone implant

\section{Background}

Eales' disease, first described by the British ophthalmologist Henry Eales in 1880, is characterized by three overlapping stages of venous inflammation (vasculitis), occlusion, and retinal neovascularization [1]. Diagnosis is mostly clinical and requires exclusion of other systemic or ocular conditions that could present with similar retinal features. In recent years, immunological, molecular biological, and biochemical studies have indicated the role of human leukocyte antigen, retinal autoimmunity, Mycobacterium tuberculosis genome, and free radical-mediated damage in the etiopathogenesis of this disease [2]. However, the etiology appears to be

\footnotetext{
* Correspondence: Kai.januschowski@med.uni-tuebingen.de

${ }^{2}$ Eye Clinic Sulzbach, Knappschaft Hospital Saar, An der Klinik 10, 66280

Sulzbach-Saar, Germany

${ }^{3}$ Centre for Ophthalmology, University Eye Hospital Tübingen, Schleichstr. 12, D-72076 Tuebingen, Germany

Full list of author information is available at the end of the article
}

multifactorial. Regarding disease staging there is no standard classification system to date. Charmis proposed a four-stage grading system in 1965 based on morphological aspects alone, which was not popular due to the overlap of stages found in typical clinical settings. More recently, Saxena and Kumar proposed a new system based on visual outcomes connected to disease severity [3]:

Stage 1 is periphlebitis of small (1a) and large caliber vessels (1b) with superficial retinal hemorrhages.

Stage 2a denotes capillary non-perfusion and stage $2 \mathrm{~b}$ neovascularization elsewhere/of the disc.

Stage $3 \mathrm{a}$ is fibrovascular proliferation and stage $3 \mathrm{~b}$ is classified as vitreous hemorrhage.

Stage 4a is tractional/combined rhegmatogenous retinal detachment whereas stage $4 \mathrm{~b}$ is rubeosis iridis,

(C) The Author(s). 2018 Open Access This article is distributed under the terms of the Creative Commons Attribution 4.0 International License (http://creativecommons.org/licenses/by/4.0/), which permits unrestricted use, distribution, and reproduction in any medium, provided you give appropriate credit to the original author(s) and the source, provide a link to the Creative Commons license, and indicate if changes were made. The Creative Commons Public Domain Dedication waiver (http://creativecommons.org/publicdomain/zero/1.0/) applies to the data made available in this article, unless otherwise stated. 
neovascular glaucoma, complicated cataract, and optic atrophy [3].

The management of Eales' disease depends on the stage of the disease and consists of medical treatment with orally administered corticosteroids in the active inflammatory stage and laser photocoagulation in the advanced retinal ischemia and neovascularization stages [4]. Eales' disease is usually diagnosed in healthy young men. Few studies considering intravitreal steroid injections exist; however, they indicate a positive effect [5]. Data about slow-release steroid implants and data on female patients are very rare. In this case report we describe the clinical findings, diagnostic management, and therapeutic management with slow-release steroid implants and the long-term evolution of an otherwise healthy 32-year-old woman who we eventually diagnosed as having Eales' disease that worsened after childbirth.

\section{Case presentation}

A 32-year-old white woman presented to our clinic in 2009 complaining about floaters in her right eye and severely reduced visual acuity in her left eye. Her visual acuity was 20/20 in her right eye and hand motion perception in her left eye. A fundus examination revealed vitreous hemorrhage in her right eye and retinal detachment in her left eye. She was admitted and emergency surgery was performed.

There was no previous ocular trauma or history of other eye diseases/eye surgery. There was no family history of eye diseases.

\section{Diagnostic and therapeutic approaches}

Scatter laser photocoagulation was performed in her right eye and at a follow-up visit in July 2009 a fluorescein angiography was performed. This showed neovascularization of the optic disc, and non-perfusion in the peripheral retina with peripheral neovascularization and central neovascularization that involved the temporal part of the macula. The best-corrected visual acuity in her right eye was 20/20; intraocular pressure was $12 \mathrm{mmHg}$ (Goldmann applanation tonometry). Perivasculitis with periphlebitis and vitreous hemorrhage was also noted. An optical coherence tomography (Heidelberg Spectralis ${ }^{\circ}$ ) scan showed atrophy of the internal retinal layers corresponding to the area of non-perfusion and a thickening of the internal limiting membrane.

Laser treatment was performed and 1 month later neovascularization of the optic disc decreased but residual perivasculitis was noted. An optical coherence tomography scan was stable except for further thickening of internal limiting membrane and incipient epiretinal membrane formation. Other laboratory workups including C-reactive protein (CRP), erythrocyte sedimentation rate (ESR), angiotensin-converting enzyme (ACE), interleukin-2 (IL-2) receptor, Treponema pallidum hemagglutination assay (TPHA), partial thromboplastin time (PTT), Venereal Disease Research Laboratory (VDRL), and interferon-gamma release assay (QuantiFERON-TB Gold) revealed no significant abnormalities. Thorax radiography revealed no suspicious lesions indicating sarcoidosis or tuberculosis. A further review of her systems was unremarkable. There were no accompanying systemic signs and symptoms except lower back pain and marginally reduced hip mobility that was diagnosed as human leukocyte antigen-B27 (HLAB27) positive sacroiliitis.

In 2010 our patient became pregnant and her disease course was stable for the duration of the pregnancy with no additional treatment needed.

At 25 months from baseline (1 month after childbirth) our patient presented with recurrence of vitreous hemorrhage and worsening of visual acuity (20/40). On fluorescein angiography there was severe perivasculitis, optic disc neovascularization, and increased area of non-perfusion. More scatter laser photocoagulation was performed and orally administered prednisone $1 \mathrm{mg} / \mathrm{kg}$ with a slow taper was started. However, stability in angiography and clinical findings was not achieved. At 28 months from baseline, she was started on methotrexate $20 \mathrm{mg} /$ week and prednisone $10 \mathrm{mg} /$ day. Because of hepatotoxicity, methotrexate was tapered and at 40 months from baseline azathioprine $100 \mathrm{mg}$ and mycophenolate mofetil $1.5 \mathrm{mg}$ was prescribed. Despite aggressive systemic therapy, the disease course was relentless. At 43 months from baseline, enlargement of nonperfusion area was noted and intense perivasculitis was noted on fluorescein angiography. On an optical coherence tomography scan loss of internal retinal layers was noted that involved the temporal half of the fovea. An epiretinal membrane with slight papillomacular traction was observed. At 44 months from baseline a dexamethasone sustained-release implant (Ozurdex ${ }^{\bullet}$, Allergan; Bucharest, Romania) was injected. This halted the disease, with a best-corrected visual acuity of $20 / 20$ progression and since then ten steroid implants have been used. We recommended injection every 4 months but because of the financial burden for our patient (no reimbursement for Ozurdex ${ }^{\circ}$ ) we injected based on worsening of angiogram, optical coherence tomography, and/or recurrent vitreous hemorrhage.

She stopped mycophenolate mofetil at 74 months from baseline after a slow taper and azathioprine at 75 months from baseline.

She underwent uneventful cataract surgery at 67 months from baseline for her right eye and at 48 months from baseline for her left eye preceded by vitrectomy for retinal 
detachment in 2009 and second vitrectomy with silicone oil injection for proliferative vitreoretinopathy at 85 months from baseline. In November 2016, fluorescein angiography was stable with minimal vasculitis, no active neovascularization, and no progression of non-perfused areas for her right eye. The last Ozurdex ${ }^{\oplus}$ was implanted 109 months from baseline. Although there are studies showing intraocular pressure increase after Ozurdex ${ }^{\oplus}$ [6], in our case there was no need for intraocular pressure-lowering medication as throughout the follow-up period pressures were between $10 \mathrm{mmHg}$ and $18 \mathrm{mmHg}$. Additional files provide comparison between fluorescein angiography before Ozurdex implantation and after the last implant was used (Additional file 1) and optical coherence tomographies showing progression from baseline to the last follow-up visit (Additional file 2). Widefield imaging and composite fundus photography can be observed in Additional file 3. Additional file 4 provides an overview of the therapeutic approaches (case report timeline.

\section{Outcomes}

Follow-up examinations were aimed at picking up early signs of disease progression and we gave timely injections of Ozurdex $^{\oplus}$ in order to preserve a functional retina taking into account the financial burden for our patient. In our case the systemic therapy was much less effective than the intravitreal sustained-release dexamethasone implant for reducing recurrences and halting disease progression. Currently our patient is completely functional at work with 20/ 20 visual acuity for her right eye and light perception for her left eye. Despite the reduced visual field, according to her statements, she is able to perform all daily activities with ease.

\section{Discussion}

Our case is peculiar due to the higher prevalence of this disease in young men and lack of previous exposure to tuberculosis that is associated with Eales' disease. To the best of our knowledge this is the first case describing continued use of a dexamethasone intravitreal slow-release system in a female patient. Also there was a severe disease course and limited response to aggressive systemic treatment that worsened after childbirth with recurrent vitreous hemorrhages and progressive loss of functional retina. Disease control could only be guaranteed by systemic steroids $(7.5 \mathrm{mg} /$ day $)$ and intravitreal sustained-release dexamethasone implant (Ozur$\left.d x^{\oplus}\right)$. The clinical picture for this patient fits the findings associated with Eales' disease that it is a diagnosis of exclusion. All laboratory workups were negative for any autoimmune or hematological diseases that could cause vitreous hemorrhage or posterior uveitis. Disease onset typically occurs during the second to third decade of life and this is also true for our patient [7-9]. The pathogenesis of vasoocclusion is still not fully understood. However, it is generally accepted that the inflammatory process leads to retinal ischemia that causes neovascularization. The newly formed vessels bleed easily, and this plays a major role in decreasing the patient's vision [10]. Of patients with Eales' disease, 80\% develop neovascularization either on the disc or elsewhere, most commonly in the peripheral retina [10]. A bilateral involvement of the eyes is common [7-9].

Saxena and Kumar have suggested a staging system useful in classifying and assessing the severity of the disease [3]. According to this classification our patient can be labeled as stage $3 \mathrm{~b}$ in her right eye and stage $4 \mathrm{~b}$ in her left eye.

Successful treatment of Eales' disease is achieved by controlling retinal perivasculitis and decreasing the risks of vitreous hemorrhage from new blood vessels [11]. For almost all neovascularizations in the retina, regardless of the cause and if there is no contraindication, laser photocoagulation, which prevents proliferation of new vessels in the ischemic retina, is the mainstay of treatment [12]. Observation and corticosteroids are the ideal treatment options for inactive retinal vasculitis and active perivasculitis, respectively [1]. In our case the combined approach of laser photocoagulation, systemic steroids, and intraocular dexamethasone implant slowed and then halted the disease course maintaining useful vision in her right eye. However, as we are observing increased formation of epiretinal membrane our patient may benefit from vitrectomy and membrane peeling in the future. Ozurdex ${ }^{\oplus}$ has proven to be safe in some studies in vitrectomized eyes for the treatment of diabetic macular edema [13] but one has to expect, in our opinion, that more injections would be needed, which would impact the patient's financial involvement (Ozurdex ${ }^{\circledR}$ is not reimbursed in Romania). In the future, even longer acting sustained-release corticosteroid implants could be an option for our patient.

\section{Conclusions}

We believe that cases of recurrent and severe Eales' disease that respond poorly to laser photocoagulation and systemic treatment could benefit from the addition of intravitreal sustained-release dexamethasone implant $\left(\mathrm{Ozurdex}^{\odot}\right)$ to the classic treatment armamentarium.

\section{Additional files}

Additional file 1: Figures 1 and 2. Fluorescein angiographies comparing before OzurDex (Additional file 2: Figure 3) and last angiography after 10 OzurDex implants were used in a period of 5 years. (JPEG $809 \mathrm{~kb}$ ) 
Additional file 2: Figure 3. Foveal OCT follow-ups showing baseline image (top), before first OzurDex (middle) and after 10 Ozurdex implants were used (bottom). (JPEG $1.10 \mathrm{mb}$ )

Additional file 3: Figure 4. Widefield imaging (Optos Daytona) of right eye. Figure 5. Composite fundus photography showing left eye (top) and right eye (bottom). (JPEG $1.30 \mathrm{mb}$ )

Additional file 4: Figure 6. Case Timeline. (JPEG 456 kb)

\section{Authors' contributions}

RI carried out planning, data acquisition and interpretation, and was responsible for drafting and revising the manuscript. KJ was involved with planning, data interpretation, and drafting and revising the manuscript. Cl was involved with data analysis and manuscript drafting and revision. Al carried out data acquisition and interpretation. All authors read and approved the final manuscript.

\section{Ethics approval and consent to participate}

Not applicable.

\section{Consent for publication}

Written informed consent was obtained from the patient for publication of this case report and any accompanying images. A copy of the written consent is available for review by the Editor-in-Chief of this journal.

\section{Competing interests}

The authors declare that they have no competing interests.

\section{Publisher's Note}

Springer Nature remains neutral with regard to jurisdictional claims in published maps and institutional affiliations.

\section{Author details}

${ }^{1}$ Opticlass, Coriolan Brediceanu no. 29, Timisoara, Romania. ${ }^{2}$ Eye Clinic Sulzbach, Knappschaft Hospital Saar, An der Klinik 10, 66280 Sulzbach-Saar, Germany. ${ }^{3}$ Centre for Ophthalmology, University Eye Hospital Tübingen, Schleichstr. 12, D-72076 Tuebingen, Germany. ${ }^{4}$ Knappschaft Eye Clinic, Knappschaft Hospital Saar, 66280 Sulzbach, Germany.

Received: 2 April 2018 Accepted: 15 July 2018

Published online: 17 October 2018

\section{References}

1. Cordero BJT, Gonzales RC. A 23-year old female patient with Eales Disease: case report. SPMC J Health Care Serv. 2015;1 (1)

2. Madhavan HN, Therese KL, Doraiswamy K. Further investigations on the association of Mycobacterium tuberculosis with Eales' disease. Indian 」 Ophthalmol. 2002;50:35-9.

3. Saxena S, Kumar D. New classification system-based visual outcome in Eales' disease. Indian J Ophthalmol. 2007;55(4):267-9.

4. Biswas J, Ravi RK, Naryanasamy A, Kulandai LT, Madhavan HN. Eales' disease - current concepts in diagnosis and management. J Ophthalmic Inflamm Infect. 2013;3:11.

5. Ishaq M, Feroze AH, Shahid M, Baig MA, Ameen SS, Feroze SH, Chishti RA. Intravitreal steroids may facilitate treatment of Eales' disease (idiopathic retinal vasculitis): an interventional case series. Eye (Lond). 2007;21:1403-5. https://doi.org/10.1038/sj.eye.6702551. published online 15 September 2006

6. Boyer DS, Yoon YH, Rubens Belfort FB Jr, Maturi RK, Augustin AJ, Li XY, Cui H, Hashad Y, Whitcup SM, Ozurdex MEAD Study Group*. Three-Year, Randomized, Sham-Controlled Trial of Dexamethasone Intravitreal Implant in Patients with Diabetic Macular Edema. Ophthalmol. 2014;121:1904-14.

7. Elliot AJ. Recurrent intraocular hemorrhage in young adults (Eales's disease); a report of thirty-one cases. Trans Am Ophthalmol Soc. 1954;52:811-75.

8. Donders PC. Eales' disease. Doc Ophthalmol Proc Ser. 1958;12:1-105.

9. Renie WA, Murphy RP, Anderson KC, et al. The evaluation of patients with Eales' disease. Retina. 1983;3(4):243-8.

10. Das T, Pathengay A, Hussain N, Biswas J. Eales' disease: diagnosis and management. Eye (Lond). 2010;24(3):472-82.

11. Das T, Biswas J, Kumar A, Nagpal PN, Namperumalsamy P, Patnaik B, et al. Eales' disease. Indian J Ophthalmol. 1994;42(1):3-18.
12. Talat $\mathrm{L}$, Lightman $\mathrm{S}$, Tomkins-netzer $\mathrm{O}$. Ischemic retinal vasculitis and its management. J Ophthalmol. 2014;2014:197675.

13. Boyer DS, Faber D, Gupta S, Patel SS, Tabandeh H, Li XY, Liu CC, Lou J, Whitcup SM, Ozurdex CHAMPLAIN Study Group. Dexamethasone intravitreal implant for treatment of diabetic macular edema in vitrectomized patients. Retina. 2011:31:915-23.
Ready to submit your research? Choose BMC and benefit from:

- fast, convenient online submission

- thorough peer review by experienced researchers in your field

- rapid publication on acceptance

- support for research data, including large and complex data types

- gold Open Access which fosters wider collaboration and increased citations

- maximum visibility for your research: over $100 \mathrm{M}$ website views per year

At $\mathrm{BMC}$, research is always in progress.

Learn more biomedcentral.com/submissions 